\title{
Hydrogen refinement during solid phase epitaxy of buried amorphous silicon layers
}

\author{
D. J. Pyke, ${ }^{1}$ J. C. McCallum, ${ }^{2}$ and B. C. Johnson ${ }^{2, a)}$ \\ ${ }^{1}$ Department of Electronic Materials Engineering, Research School of Physical Sciences, Australian \\ National University, Canberra ACT 0200, Australia \\ ${ }^{2}$ School of Physics, University of Melbourne, Victoria 3010, Australia
}

(Received 18 May 2010; accepted 16 June 2010; published online 16 August 2010)

\begin{abstract}
The effect of hydrogen on the kinetics of solid phase epitaxy (SPE) have been studied in buried amorphous Si layers. The crystallization rate of the front amorphous/crystalline $(\mathrm{a} / \mathrm{c})$ interface is monitored with time resolved reflectivity. Secondary ion mass spectrometry (SIMS) is used to examine $\mathrm{H}$ implanted profiles at selected stages of the anneals. The $\mathrm{H}$ retardation of the SPE rate is determined up to a $\mathrm{H}$ concentration of $2.3 \times 10^{20} \mathrm{~cm}^{-3}$ where the SPE rate decreases by $80 \%$. Numerical simulations are performed to model the $\mathrm{H}$ diffusion, the moving a/c interfaces and the refinement of the $\mathrm{H}$ profile at these interfaces. Despite the high $\mathrm{H}$ concentration involved, a simple Fickian diffusion model results in good agreement with the SIMS data. The segregation coefficient is estimated to be 0.07 at $575{ }^{\circ} \mathrm{C}$. A significant fraction of the $\mathrm{H}$ escapes from the a-Si layer during SPE especially once the two a/c interfaces meet which is signified by the lack of H-related voids after a subsequent high temperature anneal. () 2010 American Institute of Physics. [doi:10.1063/1.3465547]
\end{abstract}

\section{INTRODUCTION}

Solid phase epitaxy (SPE) is an important step in device fabrication where a high activation of implanted dopants on a low thermal budget can be achieved. ${ }^{1}$ SPE is the reordering of atoms in the amorphous phase onto an underlying crystalline template, layer by layer and has an Arrhenius dependence with an activation energy of $2.7 \mathrm{eV}$ and a preexponential factor of $4.64 \times 10^{6} \mathrm{~m} / \mathrm{s}^{2}$ Dopants at concentrations up to their solid solubility limit tend to enhance the SPE rate. ${ }^{3,4}$ Conversely, the presence of nondoping impurities in the amorphous phase, such as hydrogen, result in SPE retardation. ${ }^{2,5-7}$ Hydrogen is often present during SPE anneals of surface a-Si layers as it readily infiltrates from the surface oxide or ambient. Cluster implantation of decaborane $\left(\mathrm{B}_{10} \mathrm{H}_{14}\right)^{8}$ or dopant-hydride plasma doping 9 also result in the presence of $\mathrm{H}$ in the amorphous layer. Hydrogen has been observed to reduce the SPE rate by as much as 50\% (Ref. 10) and also affects the dopant-enhanced SPE rate. ${ }^{7,11}$ $\mathrm{H}$ infiltration has also been observed during vacuum anneals where the concentration can reach $1 \times 10^{19} \mathrm{~cm}^{-2} .{ }^{12}$ When a dopant is present, such as in the formation of shallow junctions, the infiltration is enhanced due to dopant-enhanced $\mathrm{H}$ diffusion. $^{13,14}$

Intrinsic $\mathrm{H}$-free SPE rates have been measured in both $4 \mu \mathrm{m}$ thick surface a-Si layers ${ }^{2}$ and buried a-Si layers. ${ }^{4,15}$ In the latter case, the c-Si capping layer prevents significant concentrations of $\mathrm{H}$ from reaching the buried a-Si layer. The behavior of implanted $\mathrm{H}$ in such a layer has not been studied until now. It might be expected that a very high $\mathrm{H}$ concentration would result at the location where the two interfaces meet after SPE. This may then yield an alternative ion cut approach to produce silicon-on-insulator wafers at low $\mathrm{H}$

${ }^{a)}$ Electronic mail: johnsonb@unimelb.edu.au. concentrations. ${ }^{16-19}$ Ion cut requires a high fluence implantation, typically mid- $10^{16} \mathrm{H} \mathrm{cm}^{-2}$, and delamination occurs at a band of H-related voids formed after a high temperature anneal. In $\mathrm{H}$ implanted a-Si, H-related nanoscale inhomogeneities also form when the $\mathrm{H}$ concentration exceeds $10^{21} \mathrm{H} \mathrm{cm}^{-3} \cdot{ }^{20,21}$ There is evidence that voids formed in a-Si can be incorporated into the crystal lattice during crystallization. ${ }^{22,23}$ Acco et al. have observed a high density of microcracks and blisters after a $500{ }^{\circ} \mathrm{C}$ anneal of a-Si containing a high concentration of $\mathrm{H}^{24}$ However, the total injected $\mathrm{H}$ fluence required for this to occur was 3.16 $\times 10^{18} \mathrm{~cm}^{-2}$ which is about two orders of magnitude greater than that required by the ion cut process where $\mathrm{H}$ is implanted into c-Si. It should also be mentioned that nanocavities formed in c-Si which is subsequently amorphized do not retain these structures. ${ }^{25}$

Here, $\mathrm{H}$ is shown to be confined between the two moving $\mathrm{a} / \mathrm{c}$ interfaces in a buried a-Si layer. The profile becomes box like while the peak concentration increases. At the same time, a portion of the $\mathrm{H}$ diffuses across the $\mathrm{a} / \mathrm{c}$ interface and is partly trapped at end of range (EOR) defects. As a consequence, the $\mathrm{H}$ concentration does not exceed its as-implanted peak concentration and void structures are not incorporated into the crystalline matrix. Nevertheless, this study shows that the diffusion parameters that Roth et al. measured for the low concentration regime, $<3 \times 10^{19} \mathrm{~cm}^{-3}$, also adequately represent the diffusion behavior at $\mathrm{H}$ concentrations $\gtrsim 1 \times 10^{20} \mathrm{~cm}^{-3}$. Their model is further refined to describe the SPE dependence on $\mathrm{H}$ for these high concentrations.

\section{EXPERIMENTAL}

Buried a-Si layers were formed in $\langle 100\rangle$-oriented p-type, B doped Si wafers with a resistivity of $1-10 \Omega \mathrm{cm}$ by the implantation of $\mathrm{Si}\left(600 \mathrm{keV}, 6 \times 10^{14} \mathrm{~cm}^{-2},-10{ }^{\circ} \mathrm{C}\right)$ and $\mathrm{Si}$ 


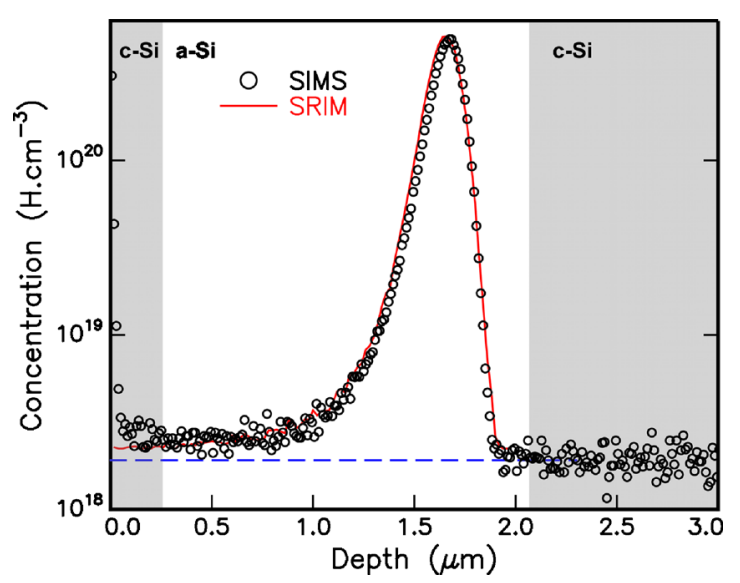

FIG. 1. (Color online) Monte Carlo simulation of $180 \mathrm{keV} \mathrm{H}$ implant into Si using SRIM (Ref. 26). The crystalline regions are shaded. The H background level of the SIMS is also indicated (dashed line).

$\left(2.0 \mathrm{MeV}, 4 \times 10^{15} \mathrm{~cm}^{-2},-10{ }^{\circ} \mathrm{C}\right)$. The buried layer was $\sim 2.0 \mu \mathrm{m}$ thick and was covered by a $\sim 0.27 \mu \mathrm{m}$ thick capping layer of c-Si as determined by Rutherford backscattering spectrometry. An additional buried a-Si layer was implanted with $\mathrm{H}$ at $180 \mathrm{keV}$ to a fluence of $1 \times 10^{16} \mathrm{~cm}^{-2}$ at room temperature. The projected range of the $\mathrm{H}$ implant is $\sim 1.68 \mu \mathrm{m}$. This implant as well as the a/c interfaces are shown in Fig. 1. There is excellent agreement between the secondary ion mass spectrometry (SIMS) data and the Monte Carlo SRIM (Ref. 26) simulation of the implant.

The SPE rates were determined in air using a timeresolved reflectivity (TRR) system using a $632.8 \mathrm{~nm} \mathrm{HeNe}$ laser. ${ }^{15}$ The samples were held on a resistively heated vacuum chuck and annealed at temperatures in the range of $520-640{ }^{\circ} \mathrm{C}$. Selected samples underwent partial anneals so that the time evolution of the $\mathrm{H}$ profile could be studied. In transforming the reflectivity versus time data to interface position versus depth the refractive index data of Jellison et al. was used for $\mathrm{c}-\mathrm{Si}$ and the values quoted by Olson et al. ${ }^{10}$ were used for a-Si. More detailed information about the TRR set-up and analysis of TRR data can be found in Ref. 15.

Secondary ion mass spectroscopy was used to measure the $\mathrm{H}$ distributions in the as-implanted and post-anneal samples. This was performed on a Cameca IMS Wf Depth Profiler, at Material Analytical Services, California (Ref. 27) using a $250 \mathrm{eV} \mathrm{Cs}$ ion beam at an angle of $58^{\circ}$ to the sample surface. The baseline sensitivity for these measurements was $\sim 2 \times 10^{18} \mathrm{H} \mathrm{cm}^{-3}$.

To establish if $\mathrm{H}$ concentrations produced by refinement during SPE were sufficient to induce void formation, crystallized samples were examined using cross-sectional transmission electron microscopy (XTEM) on a Philips CM300 operating at $300 \mathrm{kV}$. Before XTEM a $1 \mathrm{~h}$ furnace anneal at $850{ }^{\circ} \mathrm{C}$ in an $\mathrm{Ar}$ ambient was performed. This anneal is part of the standard ion cut process.

\section{RESULTS AND DISCUSSION}

Figure 2(a) shows the change in reflectivity of intrinsic and $\mathrm{H}$ implanted buried a-Si layers during an anneal at $575^{\circ} \mathrm{C}$. Each cycle of the reflectivity trace corresponds to
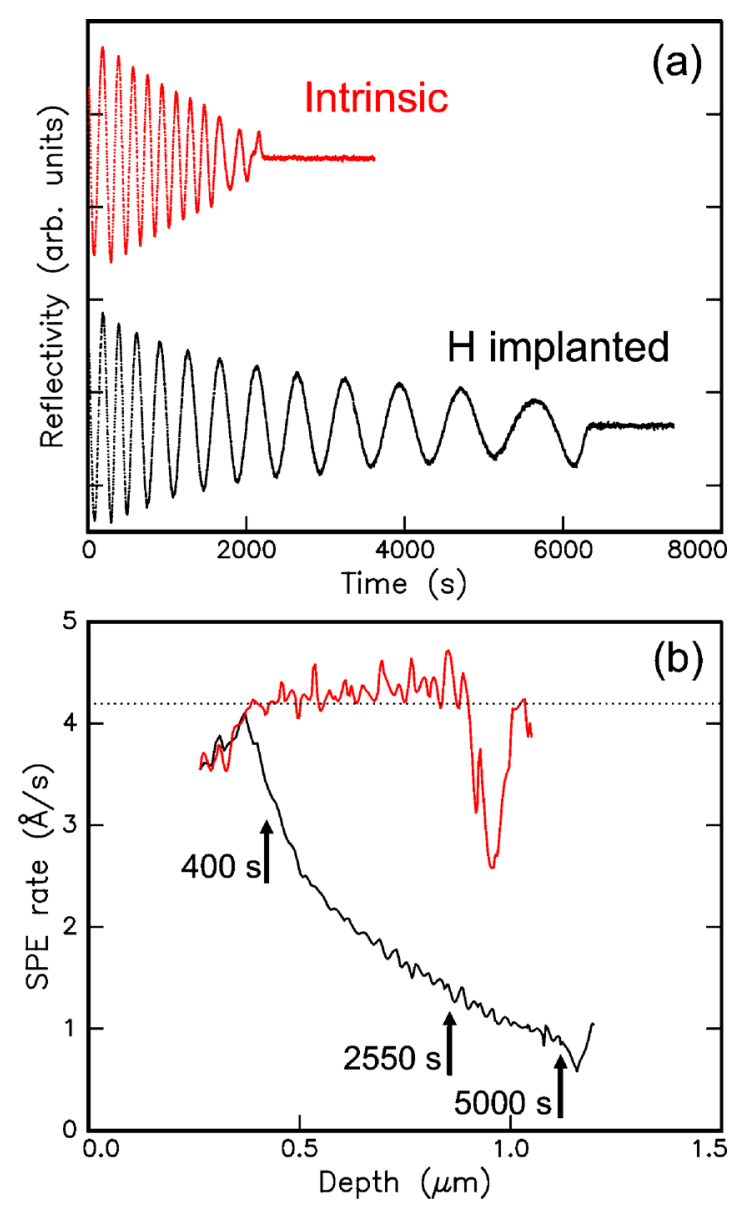

FIG. 2. (Color online) (a) TRR reflectivity trace and (b) corresponding SPE rates for intrinsic (red) and $\mathrm{H}$ implanted (black) buried a-Si layers annealed at $575{ }^{\circ} \mathrm{C}$. The expected intrinsic rate calculated using an activation energy of $2.7 \mathrm{eV}$ is also indicated (dotted line). The arrows indicate the times of the partial anneals used to form the $\mathrm{H}$ profiles shown in Fig. 3.

$78 \mathrm{~nm}$ of a/c interface movement. It is clear from this plot that the $\mathrm{H}$ severely retards the SPE rate and that the time required for the front a/c interface to move $78 \mathrm{~nm}$ increases with increasing annealing time. The corresponding front $\mathrm{a} / \mathrm{c}$ interface velocity versus depth for the two samples are shown in Fig. 2(b). These curves were obtained by matching the measured reflectivity versus time data to the theoretical reflectivity versus depth data. Initially, SPE rates in both samples increase due to the planarisation of the $\mathrm{a} / \mathrm{c}$ interface. ${ }^{10}$ The intrinsic SPE rate becomes relatively constant and agrees well with the rate determined with an activation energy of $2.7 \mathrm{eV}$ (dotted line). ${ }^{6}$ As the front interface meets the back interface at $1.05 \mu \mathrm{m}$ the SPE rate becomes irregular. After the initial increase, the SPE rate in the $\mathrm{H}$ implanted sample exhibits increasing retardation due to the increasing concentration of $\mathrm{H}$ at the a/c interface as it becomes segregated there. By the end of the anneal the SPE rate has dropped to $\sim 24 \%$ of the intrinsic velocity, meeting the back a/c interface at $1.2 \mu \mathrm{m}$. The greater range of motion of the front $\mathrm{a} / \mathrm{c}$ interface in the $\mathrm{H}$-implanted sample arises because the back a/c interface motion is retarded earlier by the proximity to the $\mathrm{H}$-implant profile allowing the front $\mathrm{a} / \mathrm{c}$ interface to crystallize more than half of the original layer thickness. In the intrinsic sample the interfaces meet in 


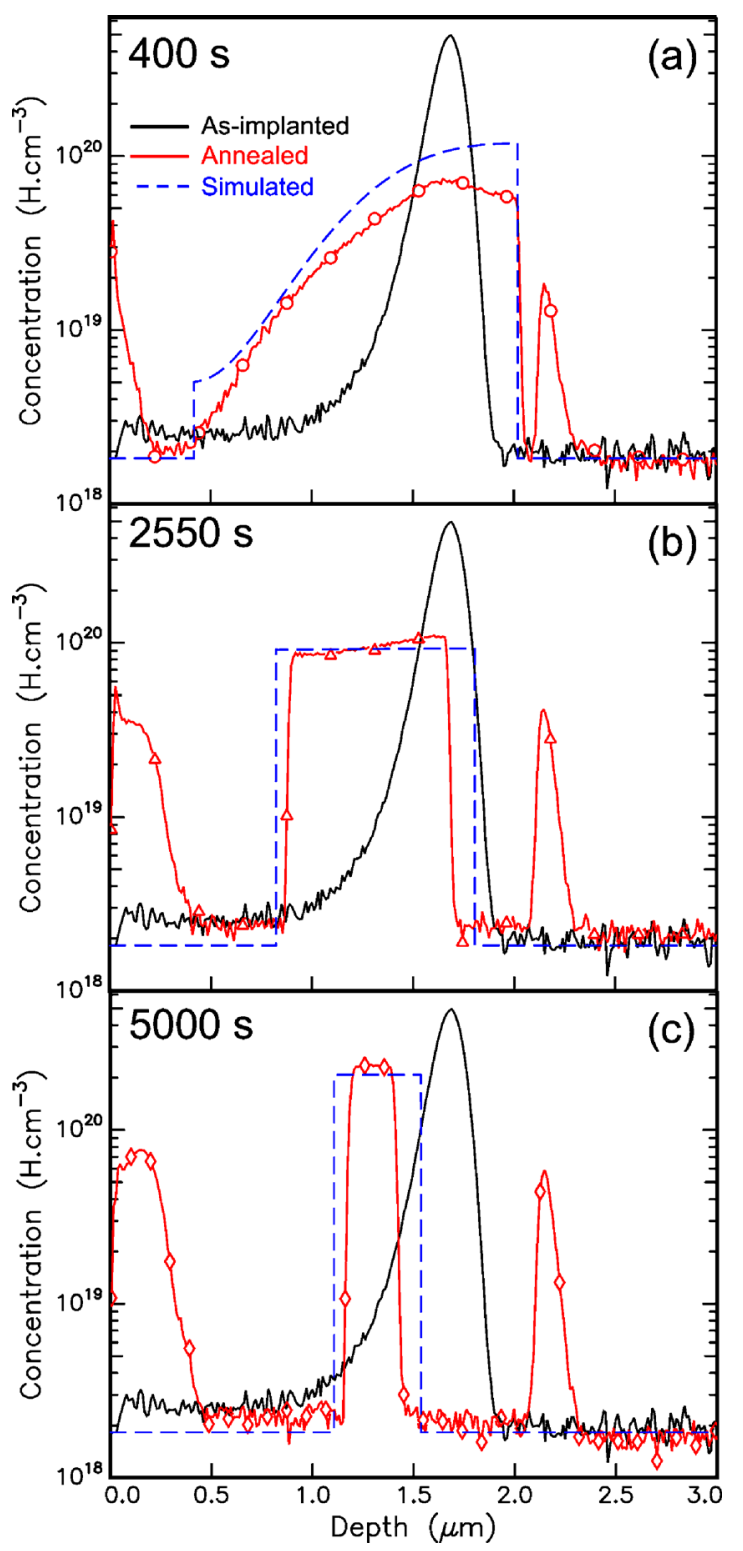

FIG. 3. (Color online) SIMS measurements of the $\mathrm{H}$ profiles in the buried a-Si layer samples after anneals at $575{ }^{\circ} \mathrm{C}$ for (a) 400, (b) 2550 , and (c) $5400 \mathrm{~s}$. The as-implanted profile is also shown in each panel (black curve). Simulated $\mathrm{H}$ profiles are overlaid for comparison (blue dashed curve).

the middle of the original a-Si layer at $1.1 \mu \mathrm{m}$. Both velocity profiles show a small dip toward the end of the anneal which is much more prominent in the intrinsic $\mathrm{H}$-free layer. This is most likely a result of the two interfaces meeting.

Figure 3 shows the SIMS data of the H-implanted sample after partial anneals at $575^{\circ} \mathrm{C}$ for 400,2550 , and $5000 \mathrm{~s}$. The as-implanted $\mathrm{H}$ profile is shown for comparison on each panel. We have also modeled the evolution of the $\mathrm{H}$ profile by numerically solving the diffusion equation with a finite difference algorithm. The results of the simulations are overlaid in Fig. 3. In this model, the $\mathrm{H}$ diffusion activation energy and pre-exponential factor were taken to be $2.70 \mathrm{eV}$ and $2.2 \times 10^{4} \mathrm{~cm}^{2} \mathrm{~s}^{-1}$, respectively. These values were previously found to be valid for $\mathrm{H}$ implanted a-Si at concentrations of $\mathrm{H}<3 \times 10^{19} \mathrm{~cm}^{-3}$. Segregation of the $\mathrm{H}$ was simply approximated as a reflection of the $\mathrm{H}$ profile about the interfaces and the segregation coefficient, $k$, was assumed to

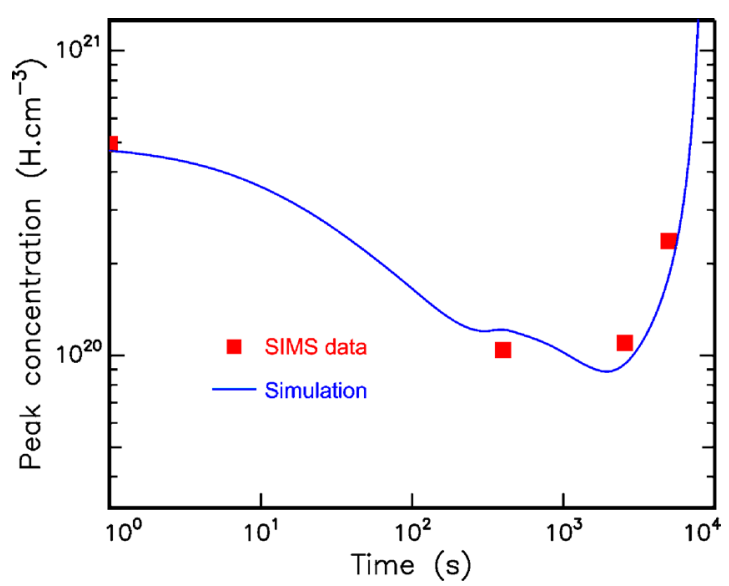

FIG. 4. (Color online) The peak $\mathrm{H}$ concentration as a function of SPE anneal time at $575^{\circ} \mathrm{C}$. The data points are taken from the SIMS data in Fig. 3 and compared to the simulated trend.

be zero, that is, no $\mathrm{H}$ is incorporated into the crystal lattice. The velocity of the SPE rate was determined iteratively at each time step in order to take into account the effect of H-retardation. This aspect of the model will be discussed further below with reference to Fig. 5 .

Figure 3(a) shows the H-profile after a $400 \mathrm{~s}$ anneal. There has already been considerable diffusion of the $\mathrm{H}$ with an expected diffusion length of $0.56 \mu \mathrm{m}$. Due to its proximity to the back $\mathrm{a} / \mathrm{c}$ interface the $\mathrm{H}$ has reached there first and has been strongly refined by the advancing interface. The interface is expected to be atomically flat and so too is the segregated $\mathrm{H}$ edge. There is SIMS broadening of about 60 $\mathrm{nm}$ caused by ion mixing and surface roughening due to ion sputtering. There is considerable $\mathrm{H}$ trapping occurring at the defect band that arises at the original position of the back interface. This is in contrast to intrinsic buried a-Si layers where much less $\mathrm{H}$ becomes trapped at this depth. ${ }^{28}$ In the near-surface region, it appears that the implanted $\mathrm{H}$ has not yet reached the front $\mathrm{a} / \mathrm{c}$ interface. However, according to the model $\sim 3 \times 10^{18} \mathrm{H} \mathrm{cm}^{-3}$ is segregated to the a-Si side of the front interface. If $\mathrm{H}$ has indeed reached the interface then this is evidence that $\mathrm{H}$ has not been fully segregated there $(k$ $>0$ ). After this point a marked decrease in the SPE rate is observed as indicated by the arrow in Fig. 2. $\mathrm{H}$ from the surface has also infiltrated the near surface c-Si region.

Figure 3(b) shows the H-profile at $2550 \mathrm{~s}$. Here, the front $\mathrm{a} / \mathrm{c}$ interface is at a depth of $\sim 0.88 \mu \mathrm{m}$ while the back interface is at $\sim 1.68 \mu \mathrm{m}$. The peak $\mathrm{H}$ concentration is $\sim 1$ $\times 10^{20} \mathrm{H} \mathrm{cm}^{-3}$. The $\mathrm{H}$ is now strongly refined at both interfaces and has a box-shaped profile. There is also clear evidence of $\mathrm{H}$ trapping at the defect band associated with the original position of the front $\mathrm{a} / \mathrm{c}$ interface at a depth of $\sim 0.2 \mu \mathrm{m}$. After $5400 \mathrm{~s}$, as shown in Fig. 3(c), the front and back $\mathrm{a} / \mathrm{c}$ interfaces are at depths of $\sim 1.15 \mu \mathrm{m}$ and $\sim 1.41 \mu \mathrm{m}$, respectively. The $\mathrm{H}$ concentration in the amorphous layer is $\sim 2.3 \times 10^{20} \mathrm{H} \mathrm{cm}^{-3}$. After this point the peak $\mathrm{H}$ concentration is expected to increase asymptotically. However, no such H-related defects indicative of high $\mathrm{H}$ concentrations are observed after the anneal as discussed below.

The loss of the $\mathrm{H}$ from the a-Si layer and the $\mathrm{H}$ trapping at the two defect bands is summarized in Table I. The as- 
TABLE I. Areal density of $\mathrm{H}$ in the a-Si layer and at the shallow and deep defect bands extracted from the SIMS data.

\begin{tabular}{ccccc}
\hline \hline $\begin{array}{c}\mathrm{t}_{\text {Anneal }} \\
(\mathrm{s})\end{array}$ & $\begin{array}{c}\mathrm{H} \text { in a-Si } \\
\left(\times 10^{15} \mathrm{~cm}^{-2}\right)\end{array}$ & $\begin{array}{c}\mathrm{H} \text { in shallow band } \\
\left(\times 10^{15} \mathrm{~cm}^{-2}\right)\end{array}$ & $\begin{array}{c}\mathrm{H} \text { in deep band } \\
\left(\times 10^{15} \mathrm{~cm}^{-2}\right)\end{array}$ & $\begin{array}{c}\text { Total } \\
\left(\times 10^{15} \mathrm{~cm}^{-2}\right)\end{array}$ \\
\hline 0 & 9.3 & 0 & 0 & 9.3 \\
400 & 8.5 & $\ldots$ & 0.3 & $\cdots$ \\
2550 & 7.5 & 0.7 & 0.4 & 8.6 \\
5400 & 5.3 & 1.5 & 0.5 & 7.3 \\
\hline \hline
\end{tabular}

implanted buried a-Si layer begins with an areal density of $9.3 \times 10^{15} \mathrm{H} \mathrm{cm}^{-2}$. After $5400 \mathrm{~s}$ about $40 \%$ of the implanted $\mathrm{H}$ has been lost from the a-Si layer. The rate of loss is surprisingly linear, with an average rate of $\Delta \Phi \approx-7.0$ $\times 10^{11} \mathrm{H} \mathrm{cm}^{-2} \mathrm{~s}^{-1}$. The rate of $\mathrm{H}$ trapping at the shallow and deep defect bands is somewhat less than this, averaging a total of $\Delta \Phi \approx 3.6 \times 10^{11} \mathrm{H} \mathrm{cm}^{-2} \mathrm{~s}^{-1}$. This is despite the $\mathrm{H}$ trapping at the shallow band having a contribution from $\mathrm{H}$ infiltrating from the surface. Hence, the two defect bands are not $100 \%$ efficient at trapping $\mathrm{H}$ with about $20 \%$ lost to the ambient or crystalline substrate. The efficiency of trapping may vary as the anneal progresses but to determine this more detailed experimentation is needed. The segregation coefficient can be estimated by considering the amount of $\mathrm{H}$ lost from the a-Si layer divided by the amount of $\mathrm{H}$ at the moving $\mathrm{a} / \mathrm{c}$ interfaces and by taking into account how far the interfaces have moved. This yields a value of $k \approx 0.07$. This value is similar to the segregation coefficient of $F$ which is another SPE rate retarding impurity. ${ }^{29}$ Although it should be mentioned that the mechanism by which $\mathrm{F}$ segregates is quite different to the $\mathrm{H}$ case. ${ }^{30}$ The loss of $\mathrm{H}$ from the a-Si layer in these stages of the anneal cannot account for the lack of $\mathrm{H}$-related defects in the annealed sample. We suggest that the reduction in $\mathrm{H}$ trapping sites in the diminishing a-Si layer in the final stages of the anneal causes the $\mathrm{H}$ to escape at a much greater rate than observed in the earlier part of the anneal. The formation of H-related voids may also require more time to coalesce.

Figure 4 illustrates the decrease in the $\mathrm{H}$ peak concentration due to $\mathrm{H}$ diffusion followed by its increase due to $\mathrm{H}$ refinement at the a/c interfaces during the SPE anneal. The data is taken from the SIMS profiles in Fig. 3 which show fair agreement with the peak concentration calculated by the model. After the initial rapid decrease due to diffusion there is a kink in the trend calculated with the model which coincides with the commencement of $\mathrm{H}$ segregation at the front interface. After a minimum is reached the peak $\mathrm{H}$ concentration rapidly increases due to the $\mathrm{H}$ refinement by both $\mathrm{a} / \mathrm{c}$ interfaces. Both the data and the calculation show this trend. However, it appears that the peak $\mathrm{H}$ concentration has not actually increased to a concentration that would result in H-related defects $\left(>10^{21} \mathrm{H} \mathrm{cm}^{-3}\right)^{32}$ since these defects are not observed after the SPE anneal (discussed below). It might then be expected that most of the $\mathrm{H}$ is lost from the a-Si layer during the very final stages of the anneal. This may be due to the decrease in $\mathrm{H}$ trapping sites in this region as the a-Si layer decreases in thickness.

Figure 5 shows the effect of $\mathrm{H}$ on the SPE rate. Our

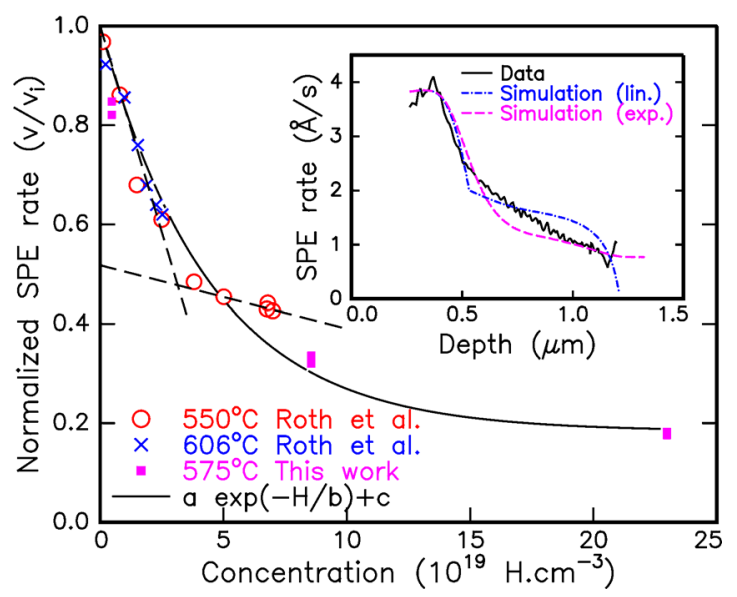

FIG. 5. (Color online) Dependence of the SPE rate on hydrogen concentrations, contrasting this work with the earlier data of Roth et al. ${ }^{5}$ The solid line is a fit to the data with an exponential curve. The dashed lines are linear trends to Roth data. The inset shows the H-retarded SPE rate data from Fig. 2(b) as well as the simulated SPE rates using both the linear fits (blue dashed-dotted curve) and the exponential fit (pink dashed curve).

results determined from Figs. 2 and 3 are compared to the data of Olson and Roth. ${ }^{6}$ Our data extends the concentration range over which the H-retarded SPE rate has been measured by a factor of three and shows that there is a continuous decrease in the SPE rate with increasing $\mathrm{H}$ concentration. Olson and Roth originally modeled their H-retardation data using two linear fits which are accurate in the low $\mathrm{H}$ concentration regime. The first linear fit is for concentrations less than $2.5 \times 10^{19} \mathrm{~cm}^{-3}$, where there is a rapid decrease in the SPE rate with increasing $\mathrm{H}$ concentration. The other fit describes a regime where the rate of decrease is much more gradual. It has been proposed that this behaviour is due to the saturation of dangling bonds at the a/c interface. ${ }^{31}$ The second fit overestimates the SPE retardation for $\mathrm{H}$ concentrations between $5-26 \times 10^{19} \mathrm{~cm}^{-3}$. We have chosen an exponential function to capture both the low and high concentration characteristics of the SPE retardation. It has the form, $a \exp (-H / b)+c$ where $a=0.82 \pm 0.02, \quad b$ $=(4.7 \pm 0.2) \times 10^{19} \mathrm{H} \mathrm{cm}^{-3}$, and $c=1-a$. This equation was used in the simulations to calculate the position of the a/c interfaces and hence the $\mathrm{H}$ profiles shown in Fig. 3. The SPE rate from Fig. 2 is shown in the inset with the simulated velocity profiles. Calculations using both the linear and the exponential fits are compared. The transition from one linear fit to the other is quite clear and manifests as a kink in the velocity profile at a depth of about $0.5 \mu \mathrm{m}$. For the linear fit, once the $\mathrm{H}$ concentration becomes high the velocity decreases to zero at $1.21 \mu \mathrm{m}$ and the front and back interfaces do not meet. The exponential dependence of the SPE rate on $\mathrm{H}$ concentration results in a velocity profile which more accurately models observation. However, the front and back a/c interfaces meet each other at a slightly deeper position of $1.32 \mu \mathrm{m}$.

Figure 6 presents a XTEM zone axis bright field (ZABF) image of a $\mathrm{H}$ implanted sample after an SPE anneal at $560{ }^{\circ} \mathrm{C}$ for $3 \mathrm{~h}$ followed by an $850{ }^{\circ} \mathrm{C}$ anneal for one hour to induce any potential hydrogen blistering. The surface is indicated with the top left arrow. The inset shows the se- 


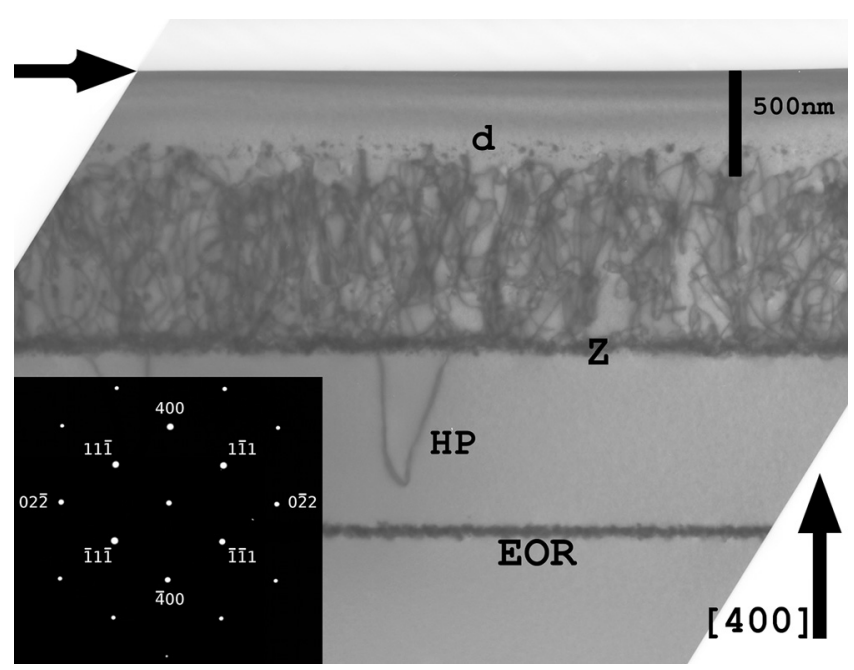

FIG. 6. TEM ZABF image of $\mathrm{H}$ implanted buried a-Si layer after a $560{ }^{\circ} \mathrm{C}$, 3 hour $/ 850{ }^{\circ} \mathrm{C}, 1 \mathrm{~h}$ anneal sequence. The top arrow indicates the surface. The inset shows the sample's SADP.

lected area diffraction pattern (SADP) that was used to determine the [400] direction as indicated. A range of defects have formed during sample processing. First, a band of defects have formed at the original a/c interfaces. The back band is most obvious and is labeled EOR defects. Such defects usually consist of dislocation type defects after a high temperature anneal. They are also often found in surface a-Si layers where they are a source of interstitials that cause transient enhanced diffusion of implanted dopants which is a limiting factor in the scaling down of device sizes. ${ }^{33}$ A clamshell or zipper $(\mathrm{Z})$ defect is present at $\sim 1.3 \mu \mathrm{m}$ where the two interfaces meet and is due to the misalignment of the two crystal seeds before crystallization and the extra interstitials implanted into the amorphous layer. ${ }^{34}$ In this image, two hairpin (HP) dislocations are clearly seen between the zipper and the back EOR defects. These defects are a result of staking faults and are usually associated with a less abrupt a/c interface for higher energy Si implants. ${ }^{35}$ The high density of defects between the original front interface and the zipper defects may be a result of the original a/c interface roughness. They do not appear to act as strong traps of $\mathrm{H}$. These defects are also present in samples that have not been implanted with H (Ref. 36) and do not affect the SPE rate. Small, possibly HP precursor defects are seen around the location of the near surface a/c interface indicated by "d." As mentioned above, no H-related voids were observed in this sample or a sample that had only undergone the SPE anneal (not shown).

\section{CONCLUSIONS}

The kinetics of SPE in the presence of $\mathrm{H}$ has been studied in detail. The dependence of the $\mathrm{H}$ concentration at the $\mathrm{a} / \mathrm{c}$ interface has been determined using a combination of time resolved reflectivity and secondary ion mass spectroscopy for $\mathrm{H}$ concentrations considerably greater than those in previous measurements. A continuous decrease with increasing $\mathrm{H}$ concentration up to the maximum of $\sim 2.3$ $\times 10^{20} \mathrm{~cm}^{-3}$ was observed. Although $\mathrm{H}$ is strongly segre- gated to the amorphous phase during SPE, $\mathrm{H}$ is continually lost from the a-Si layer throughout the anneal, entering the crystalline phase where it diffuses rapidly. A component of this $\mathrm{H}$ is trapped at the defect bands that develop at the original $\mathrm{a} / \mathrm{c}$ interface positions. The escape of $\mathrm{H}$ limits the amount of $\mathrm{H}$ that can be refined within the collapsing a-Si layer and hence no H-related voids are formed in the crystalline lattice. A model was developed to describe $\mathrm{H}$ diffusion, $\mathrm{H}$ retarded SPE, and $\mathrm{H}$ segregation simultaneously. The model showed fair agreement with both the SPE rate and the $\mathrm{H}$ profile after partial anneals. The $\mathrm{H}$ segregation coefficient at $575{ }^{\circ} \mathrm{C}$ was estimated to be $k \approx 0.07$. We are currently developing a model to describe the segregation coefficient of $\mathrm{H}$ in surface a-Si layers. ${ }^{37}$

\section{ACKNOWLEDGMENTS}

The authors would like to thank the Department of Electronic Engineering, ANU, for providing access to ion implantation facilities and Bianca Haberl for the TEM analysis. This research was supported by a grant from the Australian Research Council.

1"International technology roadmap for semiconductors," (Semiconductor Industry Association, San Jose, 2007).

${ }^{2}$ J. A. Roth, G. L. Olson, D. C. Jacobson, and J. M. Poate, Appl. Phys. Lett. 57, 1340 (1990).

${ }^{3}$ L. Csepregi, E. F. Kennedy, T. J. Gallagher, J. W. Mayer, and T. W. Sigmon, J. Appl. Phys. 48, 4234 (1977).

${ }^{4}$ B. C. Johnson and J. C. McCallum, Phys. Rev. B 76, 045216 (2007).

${ }^{5}$ J. A. Roth, G. L. Olson, D. C. Jacobson, and J. M. Poate, Amorphous Research Society, MRS Symposia. Proceedings. No. 297 (Materials Research Society, Pittsburgh, 1993), p. 291.

${ }^{6}$ G. Olson and J. Roth, in Handbook of Crystal Growth, edited by D. Hurle (Elsevier, New York, 1994), Vol. 3, Chap. 7, pp. 255-312.

${ }^{7}$ B. C. Johnson and J. C. McCallum, J. Appl. Phys. 96, 2381 (2004).

${ }^{8} \mathrm{~J}$. Matsuo, D. Takeuchi, T. Aoki, and I. Yamada, IEEE Proceedings of the 11th International Conference on Ion Implantation (IEEE Service Center, Piscataway, NJ, 1997), Vol. 1, p. 768.

${ }^{9}$ S. Heo, S. Baek, D. Lee, G. Buh, Y. Shin, and H. Hwang, Jpn. J. Appl. Phys., Part 2 45, L373 (2006).

${ }^{10}$ G. L. Olson and J. A. Roth, Mater. Sci. Rep. 3, 1 (1988).

${ }^{11}$ B. Johnson, P. Caradonna, D. Pyke, J. McCallum, and P. Gortmaker, Thin Solid Films 518, 2317 (2010).

${ }^{12}$ J. Roth, G. L. Olson, D. C. Jacobson, J. M. Poate, and C. Kirschbaum, Kinetic of Phase Transformations, MRS Symposia Proceedings (Materials Research Society, Pittsburgh, 1992), Vol. 205, p. 45.

${ }^{13}$ B. C. Johnson, P. Caradonna, and J. C. McCallum, Mater. Sci. Eng., B 157, 6 (2009).

${ }^{14}$ B. C. Johnson, J. C. McCallum, A. J. Atanacio, and K. E. Prince, Appl. Phys. Lett. 95, 101911 (2009).

${ }^{15}$ J. C. McCallum, Appl. Phys. Lett. 69, 925 (1996).

${ }^{16}$ M. Bruel, Electron. Lett. 31, 1201 (1995).

${ }^{17}$ M. Bruel, MRS Bull. 23, 35 (1998).

${ }^{18}$ V. P. Popov, I. V. Antonova, A. A. Frantsuzov, L. N. Safronov, A. I. Popov, O. V. Naumova, A. K. Antonenko, D. V. Kilanov, and I. V. Mironova, Russ. Microelectron. 31, 232 (2002).

${ }^{19}$ M. Nastasi, T. Höchbauer, R. D. Verda, A. Misra, J.-K. Lee, J. W. Mayer, and S. S. Lau, Nucl. Instrum. Methods Phys. Res. B 219-220, 604 (2004).

${ }^{20}$ S. Acco, D. L. Williamson, P. A. Stolk, F. W. Saris, M. J. van den Boogaard, W. C. Sinke, W. F. van der Weg, S. Roorda, and P. C. Zalm, Phys. Rev. B 53, 4415 (1996).

${ }^{21}$ S. Acco, W. Beyer, E. E. van Faassen, and W. F. van der Weg, J. Appl. Phys. 82, 2862 (1997).

${ }^{22}$ D. L. Young, P. Stradins, Y. Xu, L. M. Gedvilas, E. Iwaniczko, Y. Yan, H. M. Branz, Q. Wang, and D. L. Williamson, Appl. Phys. Lett. 90, 081923 (2007).

${ }^{23}$ D. L. Young, P. Stradins, Y. Xu, L. Gedvilas, B. Reedy, A. H. Mahan, H. M. Branz, Q. Wang, and D. L. Williamson, Appl. Phys. Lett. 89, 161910 
(2006).

${ }^{24}$ S. Acco, D. L. Williamson, W. G. J. H. M. van Sark, W. C. Sinke, W. F. van der Weg, A. Polman, and S. Roorda, Phys. Rev. B 58, 12853 (1998).

${ }^{25}$ X. Zhu, J. S. Williams, D. J. Llewellyn, and J. C. McCallum, Appl. Phys. Lett. 74, 2313 (1999).

${ }^{26}$ J. F. Ziegler, J. P. Biersack, and U. Littmark, "The stopping and range of ions in solids (srim)," (1996), http://www.srim.org/

${ }^{27}$ Materials Analytical Services, Incorporated, "Semiconductors \& Microelectronics," Website (Accessed 27 April 2010), http://www.mastest.com

${ }^{28}$ J. C. McCallum, Nucl. Instrum. Methods Phys. Res. B 148, 350 (1999).

${ }^{29}$ S. Mirabella, G. Impellizzeri, E. Bruno, L. Romano, M. G. Grimaldi, F. Priolo, E. Napolitani, and A. Carnera, Appl. Phys. Lett. 86, 121905 (2005).

${ }^{30}$ M. Mastromatteo, D. De Salvador, E. Napolitani, F. Panciera, G. Bisognin, A. Carnera, G. Impellizzeri, S. Mirabella, and F. Priola, Phys. Rev. B (submitted)
${ }^{31}$ J. Oberlin, A. Chami, E. Ligeon, and C. Prunier, Nucl. Instrum. Methods Phys. Res. B 19, 462 (1987).

${ }^{32}$ M. Bruel, Nucl. Instrum. Methods Phys. Res. B 108, 313 (1996).

${ }^{33}$ C. Bonafos, M. Omri, B. de Mauduit, G. BenAssayag, A. Claverie, D. Alquier, A. Martinez, and D. Mathiot, J. Appl. Phys. 82, 2855 (1997).

${ }^{34}$ K. S. Jones, S. Prussin, and E. R. Weber, Appl. Phys. A: Mater. Sci. Process. 45, 1 (1988).

${ }^{35}$ W. Maszara, C. Carter, D. Sadana, J. Liu, V. Ozguz, J. Wortmau, and G. Rozgonyi, in Energy Beam-Solid Interactions and Transient Thermal Processing, MRS Symposia Proceedings No. 25, edited by D. Biegelsen, G. Rozgonyi, and C. Shank (Materials Research Society, Pittsburgh, PA, 1984), p. 285.

${ }^{36}$ M. El-Ghor, O. Holland, C. White, and S. Pennycook, J. Mater. Res. 5, 352 (1990).

${ }^{37}$ B. C. Johnson, M. Mastromatteo, D. De Salvador, E. Napolitani, A. Carnera, and J. C. McCallum, ECS Trans.-Las Vegas, NV (accepted). 